\title{
(6) OPEN ACCESS \\ Comparison of three current sets of electrocardiographic interpretation criteria for use in screening athletes
}

\author{
Nathan R Riding, ${ }^{1,2}$ Nabeel Sheikh, ${ }^{3}$ Carmen Adamuz, ${ }^{4}$ Victoria Watt, ${ }^{4}$ \\ Abdulaziz Farooq, ${ }^{1}$ Gregory P Whyte, ${ }^{2}$ Keith P George, ${ }^{2}$ Jonathan A Drezner, ${ }^{5}$ \\ Sanjay Sharma, ${ }^{3}$ Mathew G Wilson ${ }^{1,4}$
}

${ }^{1}$ Athlete Health and Performance Research Centre, ASPETAR, Qatar Orthopaedic and Sports Medicine Hospital, Doha, Qatar

${ }^{2}$ Research Institute for Sport and Exercise Science, Liverpool John Moores University, UK ${ }^{3}$ Department of Cardiovascular Sciences, St Georges University of London, UK

${ }^{4}$ Department of Sports Medicine, ASPETAR, Qatar Orthopaedic and Sports Medicine Hospital, Doha, Qatar ${ }^{5}$ Department of Family Medicine, University of Washington, Seattle, Washington USA

\section{Correspondence to} Professor Mathew Wilson, ASPETAR, Qatar Orthopaedic and Sports Medicine Hospital, PO Box 29222, Doha, Qatar; mathew.wilson@aspetar.com

Received 8 July 2014 Revised 24 October 2014 Accepted 30 October 2014 Published Online First 11 December 2014

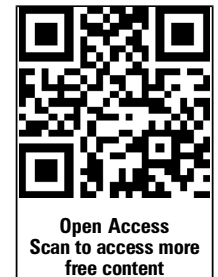

CrossMark

To cite: Riding NR, Sheikh N, Adamuz C, et al. Heart 2015;101:384-390.

\begin{abstract}
Background An increasing number of sporting bodies report unacceptably high levels of false-positive ECGs when undertaking pre-participation cardiac screening. To address this issue, modified ECG interpretation criteria have become available for use within athletes.

Objective This study assessed the accuracy of the new 2014 'Refined Criteria' against the 2013 Seattle Criteria and the 2010 European Society of Cardiology (ESC) recommendations in a cohort of Arabic, black and Caucasian athletes.

Methods 2491 male athletes (1367 Arabic, 748 black and 376 Caucasian) undertook pre-participation screening including a 12-lead ECG, with further investigation(s) upon indication.

Results Ten athletes $(0.4 \%)$ were identified with cardiac pathology; seven with hypertrophic cardiomyopathy (HCM; five black and two Arabic) and three Arabs with Wolff-Parkinson-White syndrome (WPW). All three ECG criteria were 100\% sensitive identifying all cases of HCM and WPW. The 2014 Refined Criteria reduced $(p<0.0001)$ the prevalence of an abnormal ECG to $5.3 \%$ vs $11.6 \%$ (Seattle Criteria) and 22.3\% (2010 ESC recommendations). The 2014 Refined Criteria significantly $(p<0.0001)$ improved specificity $(94.0 \%)$ across all ethnicities compared with the Seattle Criteria (87.5\%) and ESC recommendations (76.6\%). Black athletes continue to present a higher prevalence $(p<0.0001)$ of abnormal ECGs compared with Arabic and Caucasian athletes (10\% vs 3.6\% and 2.1\%).
\end{abstract}

Conclusions The 2014 Refined Criteria for athlete ECG interpretation outperformed both the 2013 Seattle Criteria and the 2010 ESC recommendations by significantly reducing the number of false-positive ECGs in Arabic, black and Caucasian athletes while maintaining 100\% sensitivity for serious cardiac pathologies.

\section{INTRODUCTION}

In 2010, the European Society of Cardiology (ESC) produced 'revised' recommendations for the interpretation of ECGs of athletes. ${ }^{1}$ This was due to the increasing number of sporting governing bodies undertaking pre-participation cardiovascular screening reporting unacceptably high levels of false-positive ECGs arising from the overlap between physiological ECG patterns commonly observed in athletes and those suggestive of cardiac pathology. To demonstrate improved specificity, the authors reanalysed the ECGs of 1005 highly trained athletes previously reported a decade earlier. ${ }^{2}$ Originally, 402 athletes (40\%) presented an abnormal ECG (so-called 'group 2' changes), which was lowered to $11 \%$ using the 2010 ESC recommendations. Work from our group and others has, however, demonstrated that certain black ethnic populations, such as African, African-Caribbean and Black Latin-American, continue to demonstrate a high prevalence of abnormal ECGs (approximately 20-40\%) when using the 2010 ESC recommendations. ${ }^{3-6}$

To address this issue, in 2012 an international team of experts produced the 'Seattle Criteria," a revision of ECG interpretation guidelines for athletes, aimed to provide greater accuracy in identifying those with cardiac pathology, while also attempting to reduce the false-positive rate. The Seattle Criteria have demonstrated favourable results over the ESC recommendations, with a reduction in the number of ECGs previously considered abnormal (17 to $4 \%$ ) in a population of high-level athletes, while still identifying all athletes with cardiac pathology. ${ }^{8}$ Furthermore, the Seattle Criteria consider specific ethnic ECG facets such as anterior (V1-V4) T-wave inversion (commonly observed in up to $13 \%$ of black athletes ${ }^{4}$ ) to represent an ethnically benign variant of the athlete's heart in those of black ethnicity, helping to reduce false-positive rates further.

Recently, Sheikh et $a l^{9}$ published additional 'Refined Criteria' for ECG interpretation, based upon their experience of screening thousands of athletes using both the ESC recommendations and the Seattle Criteria. Sheikh $e t a l^{9}$ demonstrated that the ECG patterns of isolated atrial enlargement (left and right), axis deviation (left and right) and RV hypertrophy (RVH) found in both the ESC recommendations and the Seattle Criteria provided an extremely low diagnostic yield for cardiac pathology. A unique feature of this investigation was a validation assessment in 103 young athletes with confirmed hypertrophic cardiomyopathy (HCM) whereby the Refined Criteria identified $98.1 \%$ of HCM cases.

While the ESC guidelines were initially considered acceptable for use within Arabic athletes, ${ }^{3}$ it is 
unknown whether the Seattle Criteria or the Refined Criteria are clinically appropriate for differentiating physiological cardiac adaptation from inherited pathology associated with sudden cardiac death (SCD) in Arabic athletes. Consequently, the aim of this investigation was to assess the accuracy of the new 2014 Refined Criteria versus the 2013 Seattle Criteria and the 2010 ESC recommendations in a large cohort of Arabic, black and Caucasian athletes when undertaking mass preparticipation cardiovascular screening.

\section{Participants}

Between November 2010 and January 2014, 2491 male athletes (exercising $\geq 6 \mathrm{~h} /$ week) presented at Aspetar Orthopaedic Sports Medicine Hospital for pre-participation cardiac screening, of whom 1367 were Arabic, 748 black and 376 Caucasian. Ethnicity was self-determined by the athlete. Arabic athletes were recruited from seven Gulf States (Qatar, Bahrain, Oman, United Arab Emirates, Kuwait, Yemen and Saudi Arabia) and seven Middle-Eastern countries (Egypt, Morocco, Algeria, Tunisia, Jordan, Palestine and Lebanon). Black athletes came from nine African countries (Sudan, Somalia, Ghana, Nigeria, Chad, Ivory Coast, Senegal, Cameroon and Ethiopia), three Caribbean countries (Trinidad and Tobago, Jamaica and Cuba) and those that self-determined their ethnicity as black from South America (Brazil, Colombia, Ecuador and Uruguay). The vast majority of Caucasian athletes came from mainland Europe, Australia and North America with a small number from South America.

\section{Pre-participation cardiovascular screening}

All players were screened using a cardiovascular pre-competition medical assessment form. Athletes completed the questionnaire regarding family history and personal symptoms, together with measurements of height, body mass, left brachial artery blood pressure in collaboration with an Arabic-speaking, French-speaking or English-speaking cardiac nurse. Precordial auscultation in supine and standing positions, and assessment for any physical characteristics of Marfan's syndrome were undertaken by a Sports Medicine Physician. From 2491 athletes presenting for pre-participation cardiac screening, 1718 (68.7\%) required both ECG and echocardiography as standard as part of sport or club requirements.

\section{Resting 12-lead ECG}

A 12-lead ECG was recorded on all athletes after a period of 5 min rest in the supine position using a GE Mac 5500 (New York, USA). A well-defined protocol for electrode placement was used throughout by a single physiologist. Six electrodes are placed on the chest in the following locations: $V_{1}$, fourth intercostal space at the right sternal border; $V_{2}$, fourth intercostal space at the left sternal border; $\mathrm{V}_{3}$, midway between $\mathrm{V}_{2}$ and $\mathrm{V}_{4} ; \mathrm{V}_{4}$, fifth intercostal space in the midclavicular line; $\mathrm{V}_{5}$, in the horizontal plane of $\mathrm{V}_{4}$ at the anterior axillary line, or if the anterior axillary line is ambiguous, midway between $\mathrm{V}_{4}$ and $\mathrm{V}_{6}$; and $\mathrm{V}_{6}$, in the horizontal plane of $\mathrm{V}_{4}$ at the midaxillary line. Four limb lead electrodes were placed on the arms and legs distal to the shoulders and hips.

\section{Echocardiography}

Echocardiographic examination was performed using a commercially available ultrasound system (Philips, USA). Images of the heart were obtained in the standard planes, ${ }^{10}$ with cardiac structure and function evaluated with previously described criteria. ${ }^{3}$
All echocardiograms were obtained and reported by a single echocardiographer.

\section{Further evaluation and follow-up}

Athletes demonstrating symptoms, a family history of SCD, ECG abnormalities and/or echocardiographic abnormalities considered to represent pathology, were investigated further. Subsequent studies included $24 \mathrm{~h}$ ECG, maximal exercise testing and cardiac MRI. A diagnosis of disease was established using published criteria. ${ }^{11} 12$

\section{Retrospective ECG examination}

All 2491 ECGs were analysed retrospectively using the ESC recommendations, followed by the Seattle Criteria and Refined Criteria. During analysis, first and last authors were blinded to pathological findings in all athletes, with MGW providing final judgement on ECG normality or abnormality using each of the three ECG criteria. Electrocardiographic parameters used to define various ECG abnormalities for the three sets of criteria are presented in table 1 .

\section{Refined Criteria}

Differences between the ESC recommendations and the Seattle Criteria can be observed in table 1. Compared with the ESC recommendations and the Seattle Criteria, the unique aspect of the Refined Criteria is that athletes would not receive further cardiovascular evaluation when presenting with the following recognised training-related ECG changes in isolation; (1) left atrial enlargement (LAE), (2) right atrial enlargement (RAE), (3) left axis deviation (LAD), (4) right axis deviation (RAD) and (5) Sokolow-Lyon voltage criteria for RVH. In line with the Seattle Criteria, a corrected (Bazett's formula) QT interval (QTc) $\geq 470 \mathrm{~ms}$ in men and $\geq 480 \mathrm{~ms}$ in women, and T-wave inversion preceded by convex ST-segment elevation in leads V1-V4 in asymptomatic black athletes do not require further investigation. However, importantly, the presence of two or more of the above ECG patterns would warrant secondary investigation (figure 1). ${ }^{9}$ It is worth noting that the Refined Criteria are not an evolution of the 2012 Seattle Criteria, but use ECG parameters from both the 2010 ESC recommendations and the Seattle Criteria.

\section{Statistical analysis}

Data were analysed using SPSS V.21.0 (Illinois, USA); presented as mean $\pm \mathrm{SD}$ (range) and percentage where appropriate. One-way analysis of variance using Bonferroni adjustments (if applicable) was used to identify differences in athlete anthropometry. A $\chi^{2}$ test was used to compare the number of abnormal ECGs between the three ECG interpretation criteria and between athlete ethnicities. Specificity and sensitivity for the three criteria were calculated in those athletes who undertook both ECG and echocardiography as part of club requirements, following which positive and negative likelihood ratios were calculated. A McNemar $\chi^{2}$ test was used to compare specificity and positive likelihood ratios between criteria. A $p$ value $<0.05$ was considered significant.

\section{RESULTS}

\section{Athlete demographics}

Overall, Arabic athletes were younger than both black and Caucasian athletes $(21.3 \pm 5.4$ vs $24.1 \pm 5.0$ and $24.3 \pm 5.4$ years, respectively; $\mathrm{p}<0.05)$. Arabic athletes had a smaller body surface area (BSA) than both black and Caucasian athletes $\left(1.87 \pm 0.26 \mathrm{~m}^{2}\right.$ vs $2.00 \pm 0.28 \mathrm{~m}^{2}$ vs $\left.2.14 \pm 0.26 \mathrm{~m}^{2}, \mathrm{p}<0.05\right)$. 
Table 1 Electrocardiographic parameters used to define various ECG abnormalities in the European Society of Cardiology recommendations, Seattle Criteria and Refined Criteria

\begin{tabular}{|c|c|c|c|}
\hline ECG abnormality & $\begin{array}{l}\text { European Society of Cardiology (ESC) } \\
\text { recommendations }\end{array}$ & Seattle Criteria & Refined Criteria \\
\hline $\begin{array}{l}\text { Left atrial } \\
\text { enlargement }\end{array}$ & $\begin{array}{l}\text { Negative portion of the P-wave in lead } \mathrm{V} 1 \geq 0.1 \mathrm{mV} \text { in } \\
\text { depth and } \geq 40 \mathrm{~ms} \text { in duration }\end{array}$ & $\begin{array}{l}\text { Prolonged P-wave duration of }>120 \mathrm{~ms} \text { in leads I or II } \\
\text { with negative portion of the P-wave } \geq 0.1 \mathrm{mV} \text { in depth } \\
\text { and } \geq 40 \mathrm{~ms} \text { in duration in lead V1 }\end{array}$ & As ESC \\
\hline $\begin{array}{l}\text { Right atrial } \\
\text { enlargement }\end{array}$ & P-wave amplitude $\geq 2.5 \mathrm{~mm}$ in leads II, III or aVF & As ESC & As ESC \\
\hline $\begin{array}{l}\text { Left QRS-axis } \\
\text { deviation }\end{array}$ & $-30^{\circ}$ to $-90^{\circ}$ & As ESC & As ESC \\
\hline $\begin{array}{l}\text { Right QRS-axis } \\
\text { deviation }\end{array}$ & $>115^{\circ}$ & $>120^{\circ}$ & As ESC \\
\hline RV hypertrophy & $\begin{array}{l}\text { Sum of R-wave in V1 and S-wave in V5 or V6 } \\
\geq 1.05 \mathrm{mV}\end{array}$ & $\begin{array}{l}\text { Sum of R-wave in } \mathrm{V} 1 \text { and S-wave in } \mathrm{V} 5>1.05 \mathrm{mV} \text { and } \\
\text { right axis deviation }>120^{\circ}\end{array}$ & As ESC \\
\hline Corrected QT interval & $>440 \mathrm{~ms}$ (men) and >460 ms (women) & $>470 \mathrm{~ms}$ (men) and $480 \mathrm{~ms}$ (women) & As Seattle \\
\hline $\begin{array}{l}\text { Complete left bundle } \\
\text { branch block }\end{array}$ & $\begin{array}{l}\text { QRS } \geq 120 \text { ms predominantly negative QRS complex in } \\
\text { lead V1 (QS or rS), and upright monophasic R-wave in } \\
\text { leads I and V6 }\end{array}$ & As ESC & As ESC \\
\hline $\begin{array}{l}\text { Complete right bundle } \\
\text { branch block }\end{array}$ & $\begin{array}{l}\text { RSR pattern in anterior precordial leads with QRS } \\
\text { duration } \geq 120 \mathrm{~ms}\end{array}$ & Not relevant & As ESC \\
\hline $\begin{array}{l}\text { Intraventricular } \\
\text { conduction delay }\end{array}$ & Any QRS duration $>120$ ms including RBBB and LBBB & Any QRS duration $\geq 140$ ms or complete LBBB & As ESC \\
\hline Pathological Q-wave & $>0.4 \mathrm{mV}$ deep in any lead except III, aVR & $\begin{array}{l}>0.3 \mathrm{mV} \text { deep and/or }>40 \mathrm{~ms} \text { duration in } \geq 2 \text { leads except } \\
\text { III and aVR }\end{array}$ & $\begin{array}{l}\geq 40 \text { ms in duration or } \\
\geq 25 \% \text { of the height of the } \\
\text { ensuing R-wave }\end{array}$ \\
\hline $\begin{array}{l}\text { Significant T-wave } \\
\text { inversion }\end{array}$ & $\begin{array}{l}\geq 2 \mathrm{~mm} \text { in } \geq 2 \text { adjacent leads (deep)or 'minor' in } \geq 2 \\
\text { leads }\end{array}$ & $\begin{array}{l}>1 \mathrm{~mm} \text { in depth in two or more leads V2-6, II and aVF } \\
\text { or I and aVL (excludes III, aVR and V1) }\end{array}$ & As Seattle \\
\hline $\begin{array}{l}\text { ST-segment } \\
\text { depression }\end{array}$ & $\geq 0.5 \mathrm{~mm}$ deep in $\geq 2$ leads & As ESC & As ESC \\
\hline $\begin{array}{l}\text { Ventricular } \\
\text { pre-excitation }\end{array}$ & PR interval $<120 \mathrm{~ms}$ with or without delta wave & PR interval $<120 \mathrm{~ms}$ with delta wave & As Seattle \\
\hline
\end{tabular}

Caucasian athletes presented a larger BSA than black athletes $(\mathrm{p}<0.05)$. Athletes competed in a range of competitive sports $(\mathrm{n}=27)$, with four high-intensity intermittent sports dominating participation rates (soccer (43.2\%), handball (13.7\%), volleyball $(9.1 \%)$ and basketball $(8.5 \%))$.

\section{Identification of cardiac pathology}

Ten athletes $(0.6 \%)$ were identified with a cardiac pathology associated with SCD; seven with HCM (five black and two Arabic) and three Arabic athletes with Wolff-Parkinson-White syndrome (WPW). All athletes with HCM presented with an abnormal ECG, but were diagnosed with pathology via a combination of echocardiography, 24 h Holter, exercise stress testing and cardiac MRI. The incidence of HCM in black athletes (0.9\%) was five times greater than in Arabic athletes (0.2\%). All athletes with HCM displayed T-wave inversion; five inferolateral, one isolated lateral and one with anterior-inferior. Six of the seven HCM athletes demonstrated 'deep' (>0.3 mV) T-wave inversion, ST-segment depression and Sokolow voltage criteria for LV hypertrophy (LVH), calculated as the amplitude of the $\mathrm{S}$-wave in $\mathrm{V} 1$ plus the amplitude of the R-wave in either V5 or V6 $\geq 3.5 \mathrm{mV}$ (mean $4.53 \mathrm{mV}$ ). These three cases of WPW demonstrated a classical delta wave, a short PR interval together with a prolonged QRS duration. All three athletes underwent electrophysiological study and ablation, returning to full competition following a 2-month postoperative recovery period.

\section{Comparison of three ECG interpretation criteria}

The number of ECGs considered abnormal using the three criteria is presented in table 2. From 2491 athletes, 555 (22.3\%) were considered to have an abnormal ECG according to the ESC recommendations. The most common ECG abnormalities were a prolonged QT interval (26.1\%), T-wave inversion (21.3\%), RAE (16.5\%) and a short PR interval (12.4\%). Black athletes were significantly more likely to present an abnormal ECG than Arabic and Caucasian athletes (29.9\% vs $19.1 \%$ and $18.6 \%$, respectively, $\mathrm{p}<0.0001$ ).

Compared with the ESC recommendations, use of the Seattle Criteria significantly reduced the number of abnormal ECGs from $22.3 \%$ to $11.6 \%$ (a $48 \%$ reduction; $\mathrm{p}<0.0001$ ). The main two ECG parameters that accounted for the majority of this improvement were an increase in the QTc cut-offs $(\geq 470 \mathrm{~ms}$ men and $\geq 480 \mathrm{~ms}$ women) and the acknowledgement that isolated anterior T-wave inversion in asymptomatic black athletes is benign. This spared $172(6.9 \%)$ athletes from further investigation. From the remaining abnormal ECGs, 54.6\% were considered abnormal due to either isolated RAE (31.8\%), LAE (13.1\%), LAD and RAD (5.2\% and 3.1\%) and RVH (1.4\%). Pathological Q waves (27.0\%) and other locations of T-wave inversion (23.2\%) were also highly prevalent. Black athletes were again significantly more likely to present an abnormal ECG than Arabic and Caucasian athletes (16.6\% vs 9.7\% and $8.5 \%$, respectively, $\mathrm{p}<0.0001)$. Yet across all three ethnicities, the number of abnormal ECGs was significantly reduced compared with the ESC recommendations $(p<0.0001)$.

Application of the Refined Criteria further reduced $(p<0.0001)$ the number of abnormal ECGs in athletes to $5.3 \%$. Compared with the ESC recommendations and the Seattle Criteria, this produced a $76 \%$ and $54 \%$ reduction in the number of abnormal ECGs, respectively. However, black 
Figure 1 Definition of an abnormal ECG using the Refined Criteria. AV, atrioventricular; LBBB, left bundle branch block; LVH, LV hypertrophy; ms, milliseconds; RBBB, right bundle branch block; PVC, premature ventricular contraction.

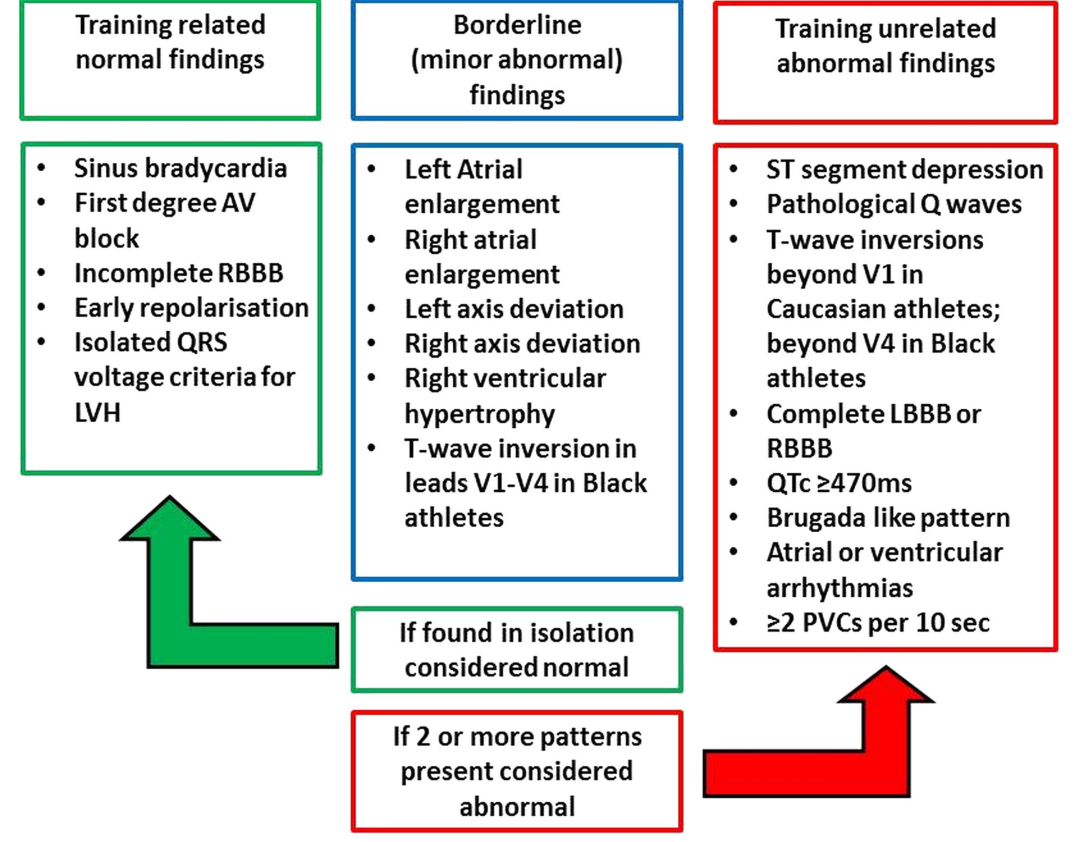

AV; atrioventricular; RBBB, right bundle branch block; LVH, left ventricular hypertrophy; LBBB, left bundle branch block; ms, milliseconds athletes continue to present a significantly higher $(\mathrm{p}<0.0001)$ prevalence of abnormal ECGs compared with Arabic and Caucasian athletes (10\% vs $3.6 \%$ and $2.1 \%)$.

\section{Sensitivity and specificity for the three ECG interpretation criteria}

From 2491 athletes screened, 1718 (68.7\%) were required to undergo both ECG and echocardiography due to club requirements. This cohort also contained all of the pathological cases (seven HCM and three WPW) and was consequently used to calculate the incidence of serious pathology together with the sensitivity and specificity of the three ECG interpretation criteria (table 3). Compared with the ESC recommendations, the Seattle Criteria significantly improved specificity from $76.6 \%$ to $87.5 \%$, while the Refined Criteria further improved specificity to $94.0 \%$. Among black athletes, the Refined Criteria offered $90.2 \%$ specificity compared with $69.5 \%$ and $83.7 \%$ for the ESC recommendations and the Seattle Criteria, respectively. This significant improvement in specificity was also seen in Arabic athletes. The Refined Criteria led to a significant improvement in specificity (95.6\%) compared with $80.2 \%$ and $88.9 \%$ for the ESC recommendations and the Seattle Criteria, respectively. However, there was $100 \%$ sensitivity for all three ECG interpretation criteria that detected all seven cases of HCM and three cases of WPW.

\section{DISCUSSION}

The correct differentiation of physiological adaptation owing to sustained and intensive exercise from an inherited or congenital cardiac pathology is paramount in order to correctly identify athletes at risk of SCD. The key finding from the current study is that the prevalence of an abnormal ECG was significantly reduced to $5.3 \%$ when using the 2014 Refined Criteria compared with the 2013 Seattle Criteria (11.6\%) and the 2010 ESC recommendations $(22.3 \%)$, respectively, while all three ECG interpretation criteria proved $100 \%$ sensitive, identifying all cases of serious cardiac pathology.

Our results demonstrate that when using the 2010 ESC recommendations, almost one in five Arabic, one in three black and one in five Caucasian athletes would require further investigation due to an abnormal ECG. These high false-positive rates certainly reinforce concerns voiced by the cardiovascular screening sceptics. While the ESC recommendations are based upon consensus rather than scientific evidence, the Seattle Criteria modified its ECG interpretation criteria by applying evidence that (1) accounted for the impact of African-Caribbean ethnicity

Table 2 Performance comparison of three ECG interpretation criteria (ESC recommendations vs Seattle Criteria vs Refined Criteria)

\begin{tabular}{|c|c|c|c|c|}
\hline & $\begin{array}{l}\text { Combined } \\
(n=2491)\end{array}$ & $\begin{array}{l}\text { Arabic } \\
(n=1367)\end{array}$ & $\begin{array}{l}\text { Black } \\
(n=748)\end{array}$ & $\begin{array}{l}\text { Caucasian } \\
(n=376)\end{array}$ \\
\hline Prevalence of an abnormal ECG using ESC recommendations & $555(22.3 \%)$ & $261(19.1 \%)$ & $224(29.9 \%)$ & $70(18.6 \%)$ \\
\hline Prevalence of an abnormal ECG using Seattle Criteria & $289(11.6 \%)$ & $133(9.7 \%)$ & $124(16.6 \%)$ & $32(8.5 \%)$ \\
\hline Prevalence of an abnormal ECG using Refined Criteria & $132(5.3 \%)$ & $49(3.6 \%)$ & $75(10 \%)$ & $8(2.1 \%)$ \\
\hline Number of identified conditions associated with SCD & 10 (7 HCM; 3 WPW) & 4 (2 HCM; 2 WPW) & 6 (5 HCM; 1 WPW) & 0 \\
\hline FPR when using ESC recommendations & $21.9 \%$ & $18.8 \%$ & $29.1 \%$ & $18.6 \%$ \\
\hline FPR when using Seattle Criteria & $11.2 \%$ & $9.4 \%$ & $15.8 \%$ & $8.5 \%$ \\
\hline FPR when using Refined Criteria & $4.9 \%$ & $3.3 \%$ & $9.2 \%$ & $2.1 \%$ \\
\hline
\end{tabular}

ESC, European Society of Cardiology; FPR, false-positive rate; HCM, hypertrophic cardiomyopathy; SCD, sudden cardiac death; WPW, Wolff-Parkinson-White syndrome. 
Table 3 Sensitivity and specificity and likelihood ratios of three ECG interpretation criteria

\begin{tabular}{|c|c|c|c|c|c|c|c|c|c|}
\hline \multirow{4}{*}{$\begin{array}{l}\text { Combined athletes: } \\
\text { Arabic, black and } \\
\text { Caucasian }\end{array}$} & \multicolumn{3}{|c|}{$\begin{array}{l}\text { ESC } \\
\text { recommendations }\end{array}$} & \multicolumn{3}{|c|}{$\begin{array}{l}\text { Seattle } \\
\text { Criteria }\end{array}$} & \multicolumn{2}{|c|}{$\begin{array}{l}\text { Refined } \\
\text { Criteria }\end{array}$} & \multirow[b]{2}{*}{-ve ECG } \\
\hline & & +ve ECG & -ve ECG & & +ve ECG & -ve ECG & & +ve ECG & \\
\hline & +ve path. & 10 & 0 & $\begin{array}{l}\text { +ve } \\
\text { path. }\end{array}$ & 10 & 0 & $\begin{array}{l}+ \text { ve } \\
\text { path. }\end{array}$ & 10 & 0 \\
\hline & -ve path. & 400 & 1308 & $\begin{array}{l}\text {-ve } \\
\text { path. }\end{array}$ & 213 & 1495 & $\begin{array}{l}\text {-ve } \\
\text { path. }\end{array}$ & 102 & 1606 \\
\hline $\begin{array}{l}\text { Positive predictive } \\
\text { value }(\%)(95 \% \mathrm{Cl})\end{array}$ & & $2.4(1.2$ to 4.4$)$ & & & $4.5(2.2$ to 8.1$)$ & & & 8.9 (4.37 to 15.81$)$ & \\
\hline $\begin{array}{l}\text { Sensitivity (\%) } \\
(95 \% \mathrm{Cl})\end{array}$ & & 100 (69.0 to 100$)$ & & & 100 (69.0 to 100$)$ & & & $100(69.0$ to 100$)$ & \\
\hline $\begin{array}{l}\text { Specificity (\%) } \\
(95 \% \mathrm{Cl})\end{array}$ & & 76.6 (74.5 to 78.6$)$ & & & $87.5^{*}(85.9$ to 89.1$)$ & & & $\begin{array}{l}94.0^{*} \dagger \\
(92.8 \text { to } 95.1)\end{array}$ & \\
\hline $\begin{array}{l}\text { Positive likelihood } \\
\text { ratio } \\
(95 \% \mathrm{Cl})\end{array}$ & & 4.3 (3.9 to 4.7 ) & & & $8.0 *(7.1$ to 9.1$)$ & & & $16.8^{*}+(13.9$ to 20.2$)$ & \\
\hline \multirow[t]{3}{*}{ Black athletes } & & +ve ECG & -ve ECG & & +ve ECG & -ve ECG & & +ve ECG & -ve ECG \\
\hline & +ve path. & 6 & 0 & $\begin{array}{l}\text { +ve } \\
\text { path. }\end{array}$ & 6 & 0 & $\begin{array}{l}\text { +ve } \\
\text { path. }\end{array}$ & 6 & 0 \\
\hline & -ve path. & 168 & 383 & $\begin{array}{l}\text {-ve } \\
\text { path. }\end{array}$ & 90 & 461 & $\begin{array}{l}\text {-ve } \\
\text { path. }\end{array}$ & 54 & 497 \\
\hline $\begin{array}{l}\text { Positive predictive } \\
\text { value }(\%)(95 \% \mathrm{Cl})\end{array}$ & & 3.4 (1.3 to 7.4$)$ & & & $6.2(2.3$ to 13.1$)$ & & & 10 (3.8 to 20.5$)$ & \\
\hline $\begin{array}{l}\text { Sensitivity (\%) } \\
(95 \% \mathrm{Cl})\end{array}$ & & 100 (54.1 to 100$)$ & & & 100 (54.1 to 100$)$ & & & 100 (54.1 to 100$)$ & \\
\hline $\begin{array}{l}\text { Specificity (\%) } \\
(95 \% \mathrm{Cl})\end{array}$ & & 69.5 (65.5 to 73.3$)$ & & & $83.7(80.3 \text { to } 86.7)^{*}$ & & & $90.2(87.4 \text { to } 92.5)^{*} \dagger$ & \\
\hline $\begin{array}{l}\text { Positive likelihood } \\
\text { ratio } \\
(95 \% \mathrm{Cl})\end{array}$ & & 3.3 (1.8 to 3.6$)$ & & & $6.1(3.2 \text { to } 7.1)^{*}$ & & & $10.2(5.3 \text { to } 12.5)^{*} \dagger$ & \\
\hline \multirow[t]{3}{*}{ Arabic athletes } & & +ve ECG & -ve ECG & & +ve ECG & -ve ECG & & +ve ECG & -ve ECG \\
\hline & +ve path. & 4 & 0 & $\begin{array}{l}\text { +ve } \\
\text { path. }\end{array}$ & 4 & 0 & $\begin{array}{l}\text { +ve } \\
\text { path. }\end{array}$ & 4 & 0 \\
\hline & -ve path. & 185 & 750 & $\begin{array}{l}\text {-ve } \\
\text { path. }\end{array}$ & 104 & 831 & $\begin{array}{l}\text {-ve } \\
\text { path. }\end{array}$ & 41 & 894 \\
\hline $\begin{array}{l}\text { Positive predictive } \\
\text { value }(\%)(95 \% \mathrm{Cl})\end{array}$ & & $2.1(0.6$ to 5.3$)$ & & & 3.7 (1.0 to 9.2$)$ & & & 8.9 (2.5 to 21.2 ) & \\
\hline $\begin{array}{l}\text { Sensitivity (\%) } \\
(95 \% \mathrm{Cl})\end{array}$ & & 100 (39.8 to 100$)$ & & & 100 (39.8 to 100$)$ & & & 100 (39.8 to 100$)$ & \\
\hline $\begin{array}{l}\text { Specificity (\%) } \\
(95 \% \mathrm{Cl})\end{array}$ & & 80.2 (75.6 to 82.7$)$ & & & $88.9 *$ (86.7 to 90.8$)$ & & & $95.6^{*}+(94.1$ to 96.8$)$ & \\
\hline $\begin{array}{l}\text { Positive likelihood } \\
\text { ratio } \\
(95 \% \mathrm{CI})\end{array}$ & & $5.1(12.2$ to 5.4$)$ & & & $9.0^{*}$ (3.8 to 10.1$)$ & & & $22.8^{*}+(9.4$ to 28.8$)$ & \\
\hline
\end{tabular}

*Significantly different from ESC recommendations.

†Significantly different from Seattle Criteria.

ESC, European Society of Cardiology; +ve ECG, abnormal ECG; -ve ECG, normal ECG; +ve path., identified cardiac pathology; -ve path., no identified cardiac pathology.

upon the electrocardiographic patterns seen in athletes ${ }^{4} \quad 13 \quad 14$ and (2) by raising the QTc thresholds ( $\geq 470 \mathrm{~ms}$ men and $\geq 480$ ms women) that would trigger further evaluation. ${ }^{15} 16$ By incorporating these two electrocardiographic features, our study demonstrates that $172(6.9 \%)$ athletes would be spared further investigation, helping to lower $(p<0.0001)$ the prevalence of abnormal ECGs by $48 \%$ compared with the ESC recommendations. This compares favourably with a recent investigation involving elite Caucasian athletes from Australia. ${ }^{8}$ Our data, however, demonstrate that almost 1 in 10 Arabic, 1 in 6 black and 1 in 11 Caucasian athletes would still require further investigation using the Seattle Criteria, primarily due to the presence of RAE (31.8\%), LAE (13.1\%), LAD (5.2\%), RAD (3.1\%) and RVH (1.4\%), either in isolation or in association with a recognised training-related ECG change.

Using HCM, arrhythmogenic right ventricular cardiomyopathy (ARVC) and pulmonary hypertension populations as a comparison group, both Zaidi et $a l^{17}$ and Gati et $a l^{18}$ have demonstrated that in asymptomatic athletes, the presence of RAE, LAE, LAD, RAD and RVH either in isolation or in association with a recognised training-related ECG change correlates extremely poorly with serious cardiac pathology. Despite this, consensus opinion for the inclusion of these ECG parameters in both the ESC recommendations and the Seattle Criteria comes from the fact that these anomalies, in particular LAE, are common ECG features in HCM. In HCM, however, they usually coexist with multitude of other ECG abnormalities such as T-wave inversion, Q-waves and ST-segment depression. ${ }^{18}$ Excluding these ECG parameters forms the basis of the Refined Criteria improving specificity and reducing the prevalence of an abnormal ECG in our cohort to $5.3 \%$ overall. More strikingly, the Refined Criteria significantly improved the abnormal ECG prevalence in black athletes to just $10 \%$ (vs 29.9\% ESC and 16.6\% Seattle Criteria), while it was further reduced to $3.6 \%$ and $2.1 \%$ in Arabic and Caucasian athletes, respectively. 


\section{Identification of pathology}

Our study identified seven athletes (0.4\%) with HCM, with the prevalence in black athletes five times greater than Arabic athletes $(0.9 \%$ vs $0.2 \%)$. No Caucasian athlete was diagnosed with HCM. HCM is cited as the leading cause of sudden death in young athletes, ${ }^{19}$ particularly within the black population. ${ }^{20}$ Importantly, all three ECG interpretation guidelines identified all seven HCM athletes with $100 \%$ sensitivity. Our incidence rates in the present study from a cohort of 1718 athletes who underwent systematic ECG and echocardiography are similar to those reported in previous screening studies involving black and Arabic athletes, who report a disease incidence of $1 \%$ and $0.5 \%$, respectively. ${ }^{6}$ While the incidence of HCM in black athletes is still approximately nine times higher than that observed in Caucasian athletes, our Arabic athletes now report similar HCM incidence rates to that of Caucasians, estimated at $0.1 \%{ }^{21}$

A further $29(1.2 \%)$ athletes were identified as having a congenital/valvular abnormality. Specifically, bicuspid aortic valve $(\mathrm{n}=7,0.3 \%)$, mitral valve prolapse $(\mathrm{n}=3,0.1 \%)$, mild aortic regurgitation $(\mathrm{n}=5,0.2 \%)$, mitral regurgitation (mild) $(\mathrm{n}=2$, $0.1 \%)$, atrial septal defect $(n=6,0.2 \%)$ and one case of dextrocardia (0.04\%); all picked up through auscultation. None of these athletes was restricted from competition. Only one of these cases was identified via an abnormal ECG (dextrocardia). This poor sensitivity underscores the importance of a physical examination within the cardiovascular screening remit.

\section{Limitations}

Our results are based on observational cross-sectional data. The potential for a false-negative result exists even though 90-95\% of individuals with HCM and 80\% with ARVC exhibit ECG abnormalities. ${ }^{22} 23$ Furthermore, without serial examination over many years, it is near impossible to ascertain whether asymptomatic athletes without a family history of SCD presenting with isolated LAD/RAD or LAE/RAE would later go on to develop a cardiomyopathy. Second, our population was exclusively men, limiting the application of our data to the female athletic population.

In the present study, one athlete, a 27-year-old black football player from South America, died unexpectedly. At the time of pre-participation screening, the athlete reported no cardiovascular symptoms and no family history of SCD. ECG and echocardiography were strictly normal. The athlete self-presented to the emergency department complaining of severe abdominal pain and died several hours later. An autopsy was performed, but the report has not been made available to the authors.

\section{CONCLUSION}

The 2014 Refined Criteria outperformed both the 2013 Seattle Criteria and the 2010 ESC recommendations by significantly reducing the number of false-positive ECGs in Arabic, black and Caucasian male athletes while remaining 100\% sensitive in identifying all athletes with cardiac pathology associated with SCD. The 2014 Refined Criteria can not only be successfully applied to black and Caucasian athletes, but also to Arabic athletes, helping to reduce both further investigation rates and the potential for unnecessary disqualifications, while maintaining sensitivity for conditions that may predispose athletes to SCD.

Acknowledgements Led by Nelly Khalil, we acknowledge the sterling efforts of Aspetar's athlete screening team in the data collection; Pascal Tahtouh, Farah Demachkieh, Nisrine Sawaya and Ezzoubair Moustaati.

Contributors NRR: study design, data collection and preparation of manuscript. NS, CA, VW and SS: interpretation of data, revision of manuscript for intellectual

\section{Key messages}

What is already known on this subject?

- The high rate of false-positive ECGs in athletes is the main criticism of pre-participation screening with ECG.

- The 2013 Seattle Criteria improved the rate of false-positive findings from that of the 2010 European Society of Cardiology (ESC) recommendations.

- It has recently been proposed that atrial enlargement, axis deviation and RV hypertrophy (RVH) should not be classified as an abnormal finding in athletes if found in isolation. Using this 'Refined' criterion, there is the potential to further reduce false-positive findings.

\section{What might this study add?}

- The new 2014 Refined Criteria significantly improved specificity (94.0\%) across all ethnicities compared with the 2012 Seattle Criteria and 2010 ESC recommendations ( $87.5 \%$ and $76.6 \%$, respectively).

- It is possible to reduce abnormal ECG prevalence rates to $3.6 \%$ and $2.1 \%$ in Arabic and Caucasian athletes. While significantly reduced, however, the prevalence of abnormal ECGs in black athletes continues to be $10 \%$ when using the 2014 Refined Criteria.

\section{How might this impact on clinical practice?}

- This study supports the rationale that when found in isolation, axis deviation, atrial enlargement and RVH are normal physiological ECG patterns in asymptomatic athletes without a family history of sudden cardiac death.

- This study also highlights that these ECG patterns ought to be incorporated into pre-existing ECG interpretational guidelines.

content. AF: data analysis. GPW: revision of manuscript for intellectual content. $K P G, J A D$ and MGW: lead for study. Study design, data collection, quality control of data and preparation of manuscript.

\section{Competing interests None.}

Ethics approval Shafallah Medical Genetics Centre and the Qatar Anti-Doping Laboratory ethics committee.

Provenance and peer review Not commissioned; externally peer reviewed.

Open Access This is an Open Access article distributed in accordance with the Creative Commons Attribution Non Commercial (CC BY-NC 4.0) license, which permits others to distribute, remix, adapt, build upon this work non-commercially, and license their derivative works on different terms, provided the original work is properly cited and the use is non-commercial. See: http://creativecommons.org/ licenses/by-nc/4.0/

\section{REFERENCES}

1 Corrado D, Pelliccia A, Heidbuchel $\mathrm{H}$, et al. Recommendations for interpretation of 12-lead electrocardiogram in the athlete. Eur Heart J 2010:31:243-59.

2 Pelliccia A, Maron BJ, Culasso F, et al. Clinical significance of abnormal electrocardiographic patterns in trained athletes. Circulation 2000;102:278-4.

3 Riding NR, Salah 0, Sharma S, et al. ECG and morphologic adaptations in Arabic athletes: are the European Society of Cardiology's recommendations for the interpretation of the 12-lead ECG appropriate for this ethnicity? Br J Sports Med 2014;48:1138-43.

4 Papadakis M, Carre F, Kervio G, et al. The prevalence, distribution, and clinical outcomes of electrocardiographic repolarization patterns in male athletes of African/ Afro-Caribbean origin. Eur Heart J 2011;32:2304-13.

5 Magalski A, McCoy M, Zabel M, et al. Cardiovascular screening with electrocardiography and echocardiography in collegiate athletes. Am J Med 2011;124:511-8. 
6 Wilson MG, Chatard JC, Carre F, et al. Prevalence of electrocardiographic abnormalities in West-Asian and African male athletes. Br J Sports Med 2012;46:341-7.

7 Drezner JA, Ackerman MJ, Anderson J. et al. Electrocardiographic interpretation in athletes: the 'Seattle criteria'. Br J Sports Med 2013;47:122-4.

8 Brosnan M, La Gerche A, Kalman J, et al. The Seattle Criteria increase the specificity of preparticipation ECG screening among elite athletes. Br J Sports Med 2014:48:1144-50

9 Sheikh N, Papadakis M, Ghani S, et al. Comparison of ECG criteria for the detection of cardiac abnormalities in elite black and white athletes. Circulation 2014; 129:1637-49.

10 Tajik AJ, Seward JB, Hagler DJ, et al. Two-dimensional real-time ultrasonic imaging of the heart and great vessels. Technique, image orientation, structure identification, and validation. Mayo Clin Proc 1978;53:271-303.

11 Maron BJ, McKenna WJ, Danielson GK, et al. American College of Cardiology/ European Society of Cardiology clinical expert consensus document on hypertrophic cardiomyopathy. A report of the American College of Cardiology Foundation Task Force on Clinical Expert Consensus Documents and the European Society of Cardiology Committee for Practice Guidelines. J Am Coll Cardiol 2003;42:1687-713.

12 Maron BJ, Zipes DP, Ackerman M. 36th Bethesda Conference: eligibility recommendations for competitive athletes with cardiovascular abnormalities. J Am Coll Cardiol 2005:45:1311-75.

13 Papadakis M, Basavarajaiah S, Rawlins J, et al. Prevalence and significance of T-wave inversions in predominantly Caucasian adolescent athletes. Eur Heart $J$ 2009;30:1728-35.

14 Di Paolo FM, Schmied C, Zerguini YA, et al. The athlete's heart in adolescent Africans: an electrocardiographic and echocardiographic study. J Am Coll Cardiol 2012:59:1029-36.
15 Basavarajaiah S, Wilson M, Whyte $\mathrm{G}$, et al. Prevalence and significance of an isolated long QT interval in elite athletes. Eur Heart J 2007;28: 2944-9.

16 Goldenberg I, Moss AJ, Peterson DR, et al. Risk factors for aborted cardiac arrest and sudden cardiac death in children with the congenital long-QT syndrome. Circulation 2008;117:2184-91.

17 Zaidi A, Ghani S, Sheikh N, et al. Clinical significance of electrocardiographic right ventricular hypertrophy in athletes: comparison with arrhythmogenic right ventricular cardiomyopathy and pulmonary hypertension. Eur Heart $J$ 2013;34:3649-56.

18 Gati S, Sheikh N, Ghani S, et al. Should axis deviation or atrial enlargement be categorised as abnormal in young athletes? The athlete's electrocardiogram: time for re-appraisal of markers of pathology. Eur Heart J 2013;34:3641-8.

19 Maron BJ, Shirani J, Poliac LC, et al. Sudden death in young competitive athletes. Clinical, demographic, and pathological profiles. Jama 1996;276: 199-204.

20 Maron BJ, Carney KP, Lever HM, et al. Relationship of race to sudden cardiac death in competitive athletes with hypertrophic cardiomyopathy. J Am Coll Cardiol 2003:41:974-80

21 Basavarajaiah S, Wilson M, Whyte G, et al. Prevalence of hypertrophic cardiomyopathy in highly trained athletes: relevance to pre-participation screening. J Am Coll Cardiol 2008;51:1033-9.

22 Maron BJ. Hypertrophic cardiomyopathy: a systematic review. Jama 2002;287:1308-20.

23 Marcus FI. Electrocardiographic features of inherited diseases that predispose to the development of cardiac arrhythmias, long QT syndrome, arrhythmogenic right ventricular cardiomyopathy/dysplasia, and Brugada syndrome. J Electrocardiol 2000;33(Suppl):1-10. 